\title{
No Claim Bonus? A Comment
}

\author{
by J.-Matthias Graf von der Schulenburg*
}

1. Professor Hey delivered an outstanding and very interesting paper on the features and effects of an optimal claiming strategy under various "experience rating" or "no claim bonus" premium schemes. The general results derived from the theoretical model framework as well as the numerical examples seem to be of value to both groups, risk and insurance economists and executives of insurance companies. In addition, the analysis should be of great interest to governmental agencies supervising insurance markets. Particularly those insurance branches using no claim discount schemes are highly regulated. Hey's paper may, therefore, also be understood as a critique on certain regulations supporting those experience rating schemes.

2. The main contributions of Professor Hey's analysis are, in my opinion, threefold: Firstly, he has modelled an insuree's problem of deciding whether he should claim, or should not claim and pay the loss out of his own pocket. To solve this difficult task, John Hey uses a clever trick. $\mathrm{He}$ introduces parameters measuring the maximum value of the expected rest lifetime utility, this being dependent, of course, on the loss-distribution, the individual time preference and the expected utility in the alternative cases of the individual claiming or not claiming in the current period. Secondly, John Hey developed a computer programme to calculate optimal claiming strategies for given loss distribution and given parameters. This is necessary as the theoretical model does not lead to a general solution of an optimal decision because of the non-linear nature of the maximum conditions. Thirdly, he has shown in a number of very interesting numerical examples the effects of no claim bonus premium schemes on the expected profit rates of the insurance company in comparison with a uniform premium.

3. I would like to make some general remarks on the subject of the paper and comment on some assumption and results of the analysis in section 5 where the effects of the introduction of no claim discount scheme are analysed. This section suggests that no claim discount schemes have only minor effects, a result which is only due to the restrictive model framework employed in the paper.

* International Institute of Management, Berlin; and University of Munich. 
4. First of all I would like to draw the reader's attention to the fact that no claim bonuses may be viewed as one form of risk sharing between the insurer and the insuree. More common forms of co-payment terms are deductibles and co-insurance. The difference between a deductible and a no claim bonus is that a deductible has to be paid in the current period whereas the insurance contract considered in the paper leads to additional payments by the insuree in a number of future periods if he or she requires insurance benefits. Simply speaking, a no claim bonus is a combination of a deductible and a credit arrangement. For this reason the general theoretical results derived for the effects of deductibles should also be valid for such schemes.

5. In section 5, two questions are analysed. Firstly, what are the effects of the introduction of a claim discount scheme on the individual level of utility if the profit rate of the insurance company is given? What answer would we expect from the general analysis of co-payment contracts? Certainly, a risk-averse individual will prefer some co-payment if the insurance premium is calculated with a proportional loading-factor. ${ }^{1}$ In other words, given a specified expected profit rate for the insurance company there must be a no claim bonus discount scheme which leads to a higher utility level than a given premium (implying no co-payment at all). Therefore, Hey's result is in accordance with standard risk and insurance theory.

In the analysis of the second question, Hey assumes a given utility level of the insuree. $\mathrm{He}$ compares two cases, full insurance coverage with a constant premium and a no claim bonus scheme. We know from the general analysis of co-payment contracts that a risk-averse individual is willing to pay more for full insurance coverage than for a co-payment contract. ${ }^{2}$ Therefore, for a given utility level of the insuree, the expected profit of the insurance company will naturally be higher for a full-insurance contract than for a risk-sharing arrangement such as a no claim bonus scheme. This, using a special and complicated example of risk-sharing arrangement, Hey shows what standard insurance theory predicts. To replace a no claim bonus contract by a constant premium scheme would only - as stated in the paper-lead to a Pareto optimal improvement if the insurer is risk-neutral and if he has exact information about the loss probabilities and the expected losses. Both are very heroic assumptions, which should be mentioned explicitly.

6. The model presented in Hey's paper assumes given accident probabilities and a given loss distribution if an accident occurs. In addition, it is implicitly assumed that both parties, the insurer and the insuree, know the loss distribution. Under these assumptions co-payment arrangements will have no direct allocative effects, they just change the distribution of the risk and the losses between the insuree and the insurer. From an economic point of view it is hard to justify co-payment arrangements in general, and no claim premium schemes in particular, if these measures do not represent an incentive for the insuree to curtail losses, or if they do not protect the insurer from estimating the risk incorrectly.

' See e.g. Arrow [1963], Mossin [1968] and Smith [1968] or the overview presented by Schulenburg [1984], 297-304.

${ }^{2}$ See Ehrlich and Becker [1972], $626 \mathrm{ff}$. 
7. Under asymetric information structures, however, that means if the insurer does not know the exact individual behaviour and the risk, two phenomena can occur: moral hazard and adverse selection. In practice, no claim discount premium schemes are chosen by insurers

- to reduce claim processing costs, as mentioned in the paper,

- to reduce the losses caused by moral hazard,

- and to reduce the losses of an insurer by averse selection processes.

Hey's analysis suggests that no claim discount premium schemes are not a very smart idea. This might be true in the absence of moral hazard and adverse selection and if costs of processing claims are small. However, co-payment arrangements lead to a better use of the scarce resources if the accident probabilities and the losses can be influenced by individual action. Even if the accident probabilities are given, the insuree is still able to influence the accident costs, depending on whether he is interested in keeping these down to a minimum or not.

\section{REFERENCES}

ARROW, K.J. [1963]: "Uncertainty and the welfare economics of medical care", American Economic Review, 53 (December 1963), 941-973.

EHRLICH, I. and BECKER, G.S. [1972]: "Market-insurance, self-insurance and self-protection", Journal of Political Economy, 80 (July 1972), 623-648.

MOSSIN, J. [1968]: "Aspects of rational insurance purchasing", Journal of Political Economy, 76 (July 1968), 553-568.

SCHULENBURG, J.-M. Graf v.d. [1984]: "Zum Verhalten von Versicherungsnachfragern in der Sozialen Marktwirtschaft", Zeitschrift für die gesamte Versicherungswissenschaft, 73 (3/4, 1984), 295-320.

SMITH, V.L. [1968]: "Optimal insurance coverage”, Journal of Political Economy, 76 (January 1968), 68-77. 